\title{
Metal-organic Frameworks as Novel Adsorbents: A Preview
}

\author{
Ebelegi Newton Augustus, Ayawei Nimibofa*, Inengite Azibaola Kesiye, Wankasi Donbebe \\ Department of Chemical Sciences, Niger Delta University, Wilberforce Island, Bayelsa State, Nigeria \\ *Corresponding author: ayawei4acad@gmail.com
}

\begin{abstract}
Adsorption processes are among the most patronized applications of Metal-Organic Frameworks. Through adsorption MOFs have found usefulness in diverse sectors of human endeavors such as; removal of noxious and harmful substances (dyes and heavy metals from liquid/gaseous media discharged from industries), storage and sequestration of gases (carbon dioxide, methane and hydrogen), separation and purification of gases/petroleum products, catalytic processes and drug delivery. Functionalized MOFs can indeed show spectacular effects owing to the introduction of more active functional groups. Therefore, the performance and applicability of MOFs as sorbents in industrial processes depends on the degree of introduced functionality, high surface area and enhanced porosity.
\end{abstract}

Keywords: metal organic framework, porous coordination polymer, organic linkers, ligands

Cite This Article: Ebelegi Newton Augustus, Ayawei Nimibofa, Inengite Azibaola Kesiye, and Wankasi Donbebe, "Metal-organic Frameworks as Novel Adsorbents: A Preview." American Journal of Environmental Protection, vol. 5, no. 2 (2017): 61-67. doi: 10.12691/env-5-2-5.

\section{Introduction}

It is now evident that composite materials have opened a new vista of prospects for the application of porous materials. Over the decades there has been a growing interest with respect to the versatility of Porous Coordination Polymers (PCPs) and this is palpably clear owing to the number of scientific publications reported and new materials discovered so far [1]. Coordination polymers, also known as Metal-Organic Frameworks (MOFs) are captivating crystalline nanomaterials made up of organic linkers(bridging ligands) and inorganic nodes (metal cations) that extend infinitely into two or three dimensions through metal-ligand bonding [2].

The organic and inorganic components of MOFs can be varied in shape, size, geometry and branching modality to produce a versatile group of porous crystalline solids which are often christened as 'Sponges' because of their ability to mop up extraordinary quantities of gas or liquid in their cavernous pores [3,4]. Anthropogenic activities have resulted to massive emission of green house gases such as carbon (IV) oxide and methane for several decades. The colossal concentration of greenhouse gases in the atmosphere has led to the constant warming of the earth surface (global warming) which has triggered climate change and some other severe environmental imbalances. Some impacts of climate change such as sea level rise, ocean surge, irreversible increase in acidity level of ocean waters and other extreme weather events are exacerbated by the incessant emission of green house gases into the atmosphere [5]. These obvious environmental challenges influenced many governments and scientists under the auspices of United Nations Framework Convention on Climate Change (UNFCCC) to sign various protocols, accords and agreements all in a bid to mitigate the adverse impact of climate change through programmes and policies that are targeted at reducing green house gas emissions. In this regard porous materials have attracted attention because of their potential use as adsorbents for $\mathrm{CO}_{2}$ separation/sequestration processes [6].

Research into $\mathrm{CO}_{2}$ capture and sequestration is a major effort aimed at resolving the urgent need to reduce $\mathrm{CO}_{2}$ emission and also facilitate carbon - neutral economies in today's world [7]. Conventional adsorbents such as carbon nanaotubes, carbon re-enforced composites [7,8], zeolite [9] and polymer-based porous materials [10] have major short comings such as, high cost, low capacity, weak interaction and difficulty in regeneration in practical applications [11,12,13].

The structure and properties of MOFs can be tailored to suit the requirements of specific applications because their pore size, pore shape, network topology and surface functionality can be tuned systematically through chemical modification. In order to surmount the short comings of traditional adsorbents, researchers have suggested MOFs as the most promising adsorbent to replace conventional adsorbents due to their unique structure, composition, surface area, tunable pore size and ultimately numerous active sites $[14,15,16]$. Therefore this preview focuses on the applications of Metal- Organic Frameworks [MOFs] in adsorption processes and their efficiency in gas adsorption, liquid adsorption and selective separation. 


\section{History of Metal-Organic Frameworks}

Metal-organic crystals with open spaces have been identified since Alfred Werner conducted his research on coordination complexes because many kinds of porous crystals were studied at the time [17]. However, none of the porous molecular crystals studied exhibited permanent porosity until Metal-Organic Frameworks were invented in the 1990s $[18,19,20]$.

The synthesis of the very first Metal -Organic Framework called MOF-2 with formula $\mathrm{Zn}(\mathrm{bdc})\left(\mathrm{H}_{2} \mathrm{O}\right)$ where bdc means 1,4-benzendicarboxylate. Subsequently other materials that showed evidence of permanent porosity were synthesized and named as MOF-3 $\left[\mathrm{Zn}_{3}(\mathrm{bdc})_{3}\right]$ and MOF-4 [Zn(btc) $\mathrm{NO}_{3}$ ) where btc means 1,3,5-benzentricarboxylate [21]. The history of Metal-Organic Frameworks changed in 1999 with the synthesis of the symbolic MOF-5 and since then MOF-5 has been recognized as the most articulated example of MOFs by most researchers of material science [22].

MOF-5 has a structure that shows $\mathrm{Zn}_{4} \mathrm{O}$ groups linked by terephthalate to form a neutral framework of composition $\mathrm{Zn}_{4} \mathrm{O}$ (bdc) $)_{3}$ where bdc means 1,4-dicarboxylate [23]. The name MOF-5 was coined in reminiscence of the popular zeolite ZSM-5 [24].

As more researcher worked on, it became obvious that MOF-5 can be adapted as a modular structure from which several other isorecticular frameworks can be synthesized by merely changing functionality and length of its organic linkers [25]. Thus, HKUST-1 $\left[\mathrm{Cu}_{3}(\mathrm{btc})_{2}\right]$ where btc means 1,3,5-benzentricarboxylate, MIL-101 [chromium(III) terephthalate], MOF-74 [ $\mathrm{Zn}_{2}$ (dhbdc)] where dhbdc means 2,5-dihydroxy-1,4-benzenedicaroxylate, several iso-structural analogs of Mg-MOF-74 [IRMOF-741] and NU-110 E were subsequently synthesized.

\subsection{Nomenclature}

Metal-Organic Frameworks have been name either by the sequential number of synthesis / chronological order of discovery, initials of institution where they were first synthesized or by sequence of isorecticular synthesis.

a. Naming by Sequential number of synthesis: In this method of naming MOFs, the number attached to the MOF indicates the chronological order of its discovery or synthesis e.g. MOF-2, MOF-3,MOF-4, MOF-5, e.t.c. b. Naming by Initials of Institution or place of discovery: Another method of naming MOFs is by forming an acronym from the name of the institution or place where the MOF was originally synthesized e.g. HKUST = HonKong University of Science and Technology, MIL= Material Institute Lavoisier, NENU = North East Normal University China.

c. Naming by sequence of Isorecticular synthesis : Some MOFs are named based on the presence of the same net topology (isorecticular) organic linkers, this means they share a common cubic topology constructed from the same type of organic links [26] e.g. IRMOF -1 and IRMOF-0. where IRMOF = IsoRecticularMOF.

\section{Synthesis of Metal-Organic Frame Works}

Although MOFs are mostly synthesized by solvothermal method, other synthesis approaches such as hydrothermal synthesis, microwave assisted synthesis, electrochemical synthesis, sonochemical synthesis and mechanochemicals synthesis have been used as options for MOF synthesis [27]. Most MOF synthesis are liquid phase reactions that involves heating a mixture of organic linkers(bridging ligands) such as carboxylates, phosphates, sulfonates or heterocyclic compounds with a metal salt in a solvent system that contains an ionizing solvent functionality as shown in Figure 1 [28].

The most popular synthesis method for MOFs are solvothermal and hydrothermal techniques in which average reaction times are usually between several hours to days as shown in Figure 2.

\subsection{MOF Synthesis Techniques}

\section{Solvothermal Synthesis}

This method of synthesis involves heating a mixture of organic linkers(bridging ligands) with a metal salt in high boiling solvent systems. The source of energy applied to drive this method is thermal energy (353K-453K) and the process could last between 48 to 96 hours. This technique usually produces fine particle powders that are not achieved by most conventional procedures.

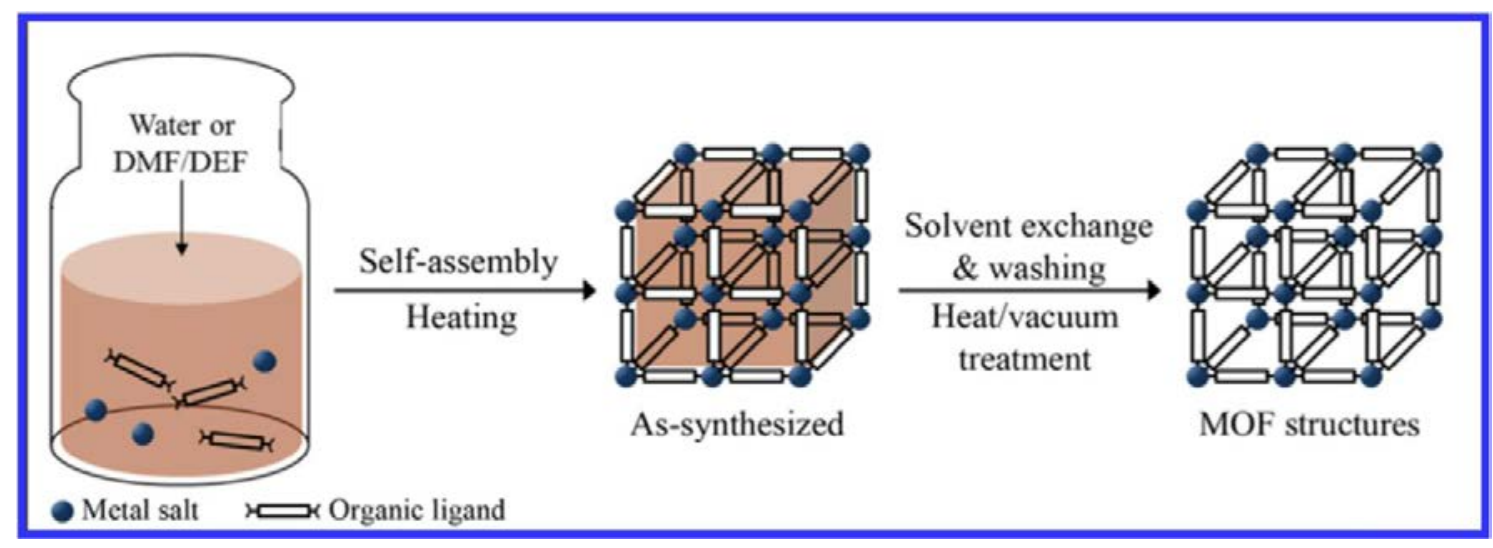

Figure 1. Schematic diagram showing Conventional solvothermal synthesis of MOFs [29] 

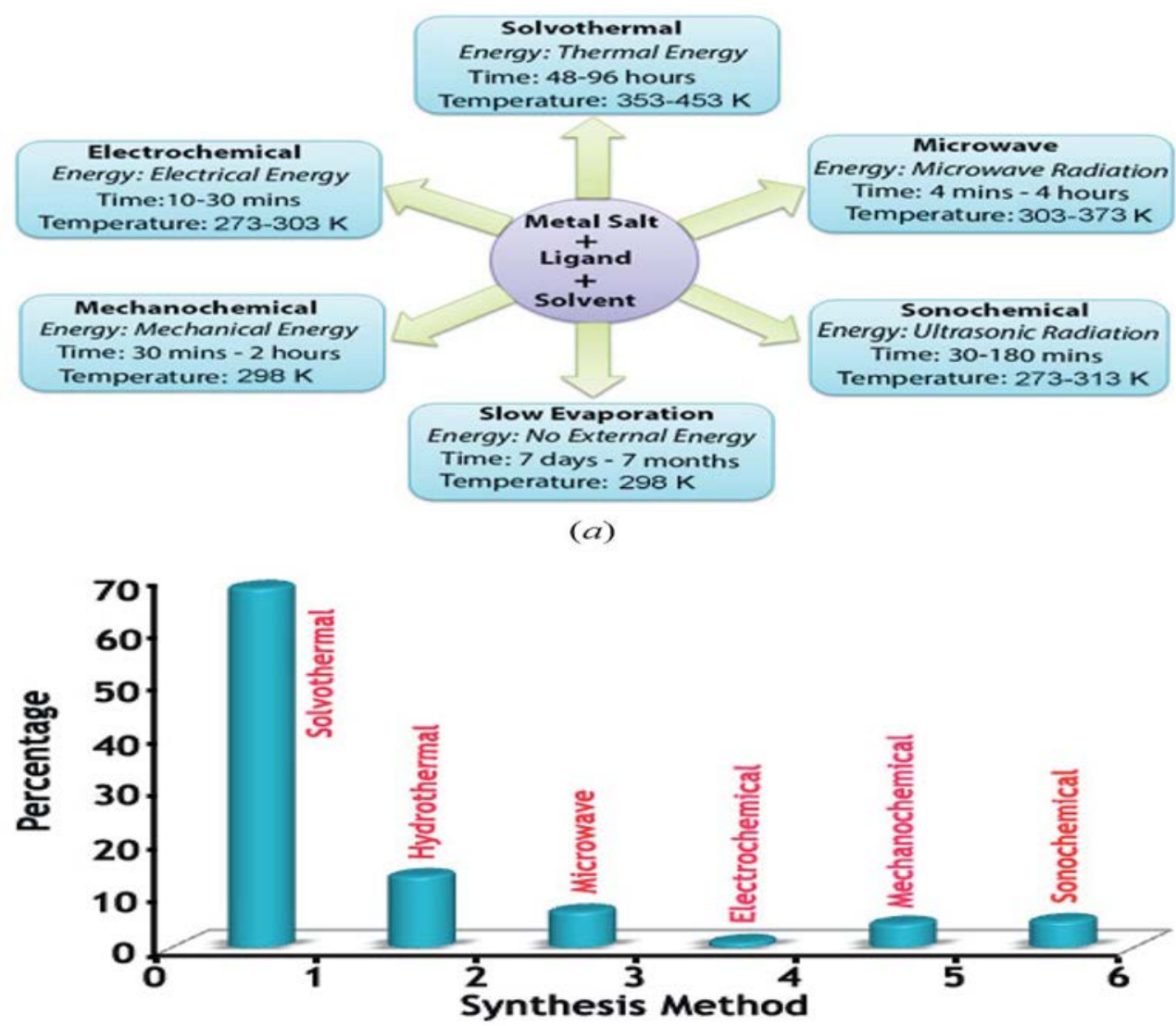

(b)

Figure 2. (a) Synthesis conditions commonly used for MOF preparation; (b) Summary of the percentage of MOFs synthesized using the various preparation routes [27]

\section{Microwave Assisted Synthesis}

This technique involves heating a solution of metal salt, ligand and solvent with microwaves (303K-373K) between 4 minutes to 4 hours, it is indeed a very rapid method of producing nanosized MOF crystals that are similar to those produced by the regular solvothermal procedure [31].

Sonochemical Synthesis

Sonochemistry is a process in which molecules undergo chemical change due to the application of intensive ultrasound radiation between $20 \mathrm{kHz}$ and $10 \mathrm{MHz}$ ) [27]. Sonochemical methods can generate homogeneous nucleation centres and a considerable reduction in crystallization time compared with conventional hydrothermal methods. MOF-5 synthesis using sonochemical irradiation in 1methyl-2-pyrrolidinone (NMP) can produce 5-25 mm crystals in $30 \mathrm{~min}$, which is similar to MOF-5 synthesized by solvothermal or microwave methods [32]

Slow Evaporation Synthesis

In this method of synthesis no external energy supply is required as is the case for other conventional synthesis techniques, a solution of the starting materials are concentrated by slow evaporation of the solvent at a fixed temperature (room temperature). In some cases the solvent is a mixture of solvents, which increases the solubility of reagents that quickens the evaporation of low boiling solvents thereby making the synthesis process faster [33]. Electrochemical Synthesis

This method of synthesis was driven by the need to prepare large MOF crystals for certain applications under mild conditions through adjustment of $\mathrm{pH} /$ solvent at room temperature. Therefore electrochemical synthesis of MOFs does not require metal salts but provides the metal ions via anodic dissolution into synthesis mixtures that contains organic linkers and electrolytes [34].

Mechanochemical Synthesis

Mechanochemical synthesis is a solvent free process where MOFs are produced via a process of performing chemical reactions by applying mechanical force. Recently, mechanochemical syntheses have been efficiently employed for the rapid synthesis of MOFs using Liquid Assisted Grinding (LAG), where a small amount of solvent is added into a solid reaction mixture. By varying the added solvent in a Liquid Assisted Grinding process onedimensional, two-dimensional and three-dimensional coordination polymers could be obtained from the same reaction mixture [35].

\subsection{Post Synthetic Modification (PSM)}

Integration of functional groups of interest is usually hard to achieve during synthesis of MOFs [36]. However, desired functionalities can be introduced into MOFs through Post Synthetic modification processes. Thus Post Synthesis Modification is the introduction of additional functional group(s) into already synthesized MOFs in order to achieve specific application targets. Post Synthetic Modification of MOFs can be done by protonation or doping in either a non-covalent interaction, coordinate interaction or covalent interaction [37]. Some notable benefits of post-synthetic modification include, introduction of multiple functionalities into the same framework, 
production of a wide range of MOFs with the same topology but bearing diverse functionalities.

\section{Application of Metal-organic Frameworks}

In recent times much attention has been focused on more possible applications of MOFs because of their unique structural assets. MOFs are becoming alluring on environmental applications especially their extraordinary gas capturing ability has been earmarked for the separation of various unwanted and environmentally harmful chemical species [38]. MOFs are preferred over zeolites, activated carbon and other conventional adsorbents because of their large surface area and well defined pore properties which makes them more useful for volume specific applications such as separation, purification and adsorption processes $[37,38]$.

\subsection{Activation of MOFs for Adsorption Processes}

Metal Organic Frame works must be activated before they are used as adsorbents. Activation of MOFs involves the removal of solvent molecules from their pores in order to open the void spaces within the crystal lattice [39]. Most encased solvent molecules are removed through evaporation. However, for cases where solvent molecules show strong interactions with either metal ions or organic linkers activation is achieved under vacuum at very high temperatures.

\subsection{Utilization of MOFs for Adsorption and Storage of Gases}

The application of MOFs as adsorbents for gases is becoming more desirous because of the need for smarter procedures that can provide elevated selectivity and better capacity. The mechanisms for selective gas adsorption by MOFs could be either by physisorption (i.e. surface interaction) or molecular sieving (size exclusion) [40]. Thus, they are very promising candidates for gas separation processes due to their large surface areas, adjustable pore size and thermal stability [41]. One sure way to restrict pore sizes of MOFs designated for gas adsorption /storage is the use of short organic linkers (bridging ligands) [42]. Some MOFs which are known to have high gas storage properties are shown in Figure 3.

A shorter length of organic linker (formate) in Microporous Manganese Formate MOF produced very small aperture sizes that can clearly screen hydrogen gas from nitrogen and also do the same screening of carbon dioxide from methane [43]. Similarly, the construction of a zinc Microporous MOF PCN-13 with bulky organic linkers (9,10- anthracene dicarboxylate), PCN-13 has a constricted pore size of $3.5 \mathrm{~A}^{0}$ therefore it is applied in the selective adsorption of hydrogen and oxygen excluding nitrogen and carbon monoxide [44].

\section{Hydrogen Storage}

The introduction of Open Metal Sites (OMSs) has the potential of boosting the hydrogen storage capacity in MOFs mostly at low pressures [45]. Running an electric vehicle with hydrogen and fuel cells instead of batteries has the advantages of cost reduction and achievement of higher energy densities [46]. Out of all the hydrogen storage techniques namely; compression, liquefaction, chemisorption in metal hydrides and physisorption, the later makes up for all the short comings of the rest techniques [47]. Hydrogen storage by adsorption (physisorption) is a process in which hydrogen molecules are bonded onto porous materials (adsorbents) by Van der waals forces [47]. Since physisorption is a non-activated process the interaction of hydrogen with the porous material is relatively weak $\left(2-8 \mathrm{KJmol}^{-1}\right)$ this results in lower sorption heat than that required by compression, liquefaction and chemisorption in metal hydrides, thus no active heating device is required to release stored hydrogen [48].MOF-177 with a surface area of $4,600 \mathrm{~m}^{2} / \mathrm{g}$ shows the highest hydrogen storage capacity compared to other porous materials shown in Table 1 below.

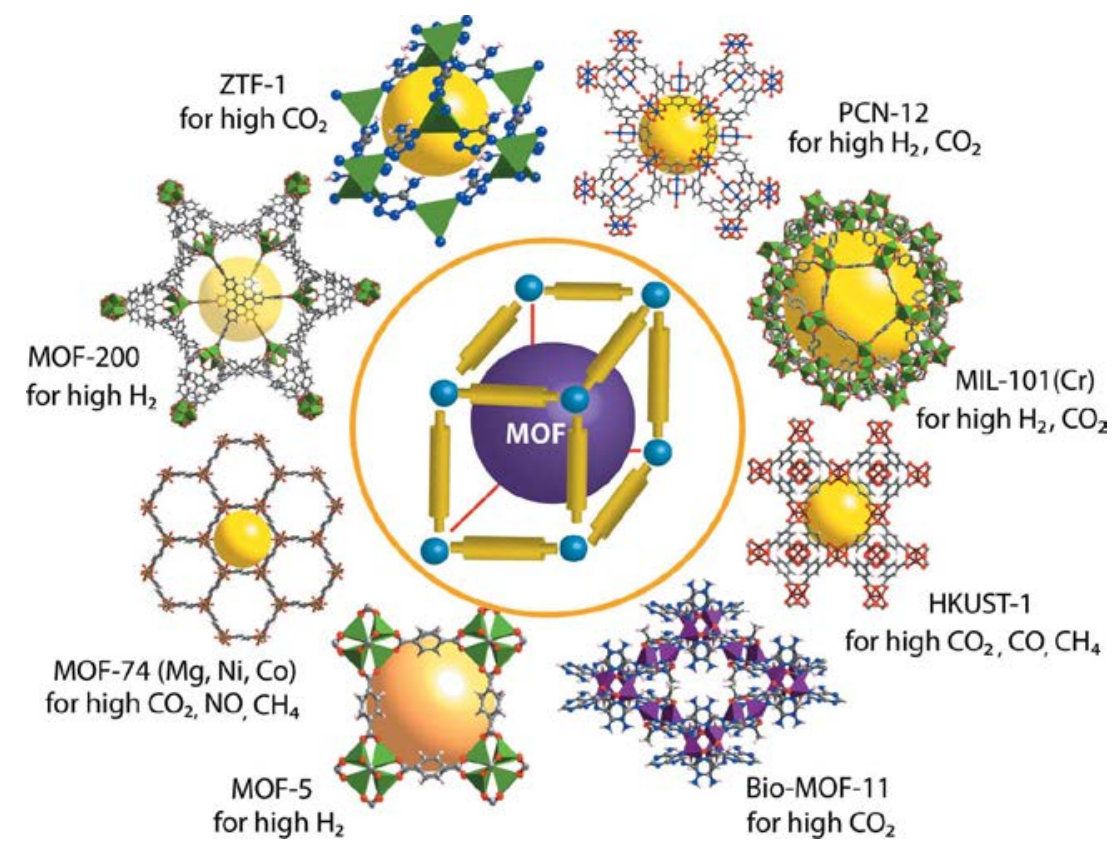

Figure 3. Schematic representation of some MOFs which are known for high gas storage properties [29] 
Table 1. Hydrogen Storage Capacity of some porous materials.

\begin{tabular}{|l|l|l|l|}
\hline Porous Material & Surface Area & Hydrogen storage capacity & Reference \\
\hline Zeolite & $<750 \mathrm{~m}^{2} / \mathrm{g}$ & $2.86 \mathrm{wt} \%$ under ideal conditions & 49 \\
\hline Silica gel & $1000 \mathrm{~m}^{2} / \mathrm{g}$ & $0.6 \mathrm{wt} \%$ at $77 \mathrm{~K}$ and $0.1 \mathrm{MPa}$ & 50 \\
\hline Boron Nitride(BN) & $1050 \mathrm{~m}^{2} / \mathrm{g}$ & $2.6 \mathrm{wt} \%$ at $10 \mathrm{MPa}$ & 51 \\
\hline Boron-Carbon Nitride (B-C-N) & $1500 \mathrm{~m}^{2} / \mathrm{g}$ & $1.0 \mathrm{wt} \%$ at $77 \mathrm{~K}$ and $0.1 \mathrm{MPa}$ & 52 \\
\hline Carbon Aerogels & $3000 \mathrm{~m}^{2} / \mathrm{g}$ & $5.0 \mathrm{wt} \%$ at $77 \mathrm{~K}$ and $4.5 \mathrm{MPa}$ & 53 \\
\hline Hyper Crossed Polymers & $2000 \mathrm{~m}^{2} / \mathrm{g}$ & $3.8 \mathrm{wt} \%$ at $77 \mathrm{~K}$ and $4.5 \mathrm{MPa}$ & 54 \\
\hline MOF-177 & $4,600 \mathrm{~m}^{2} / \mathrm{g}$ & $19.6 \mathrm{wt} \%$ at $77 \mathrm{~K}$ and $100 \mathrm{bar}$ & 55 \\
\hline
\end{tabular}

\section{Methane Storage}

Methane is a clean gas that is a promising alternative to gasoline and it can be found in lakes, swamps, landfills and fossil fuel. Storing large quantities of methane in tanks for vehicular applications could be a challenging task because of its low energy density, therefore the need to develop new methods of storing large quantities of methane has been facilitated through methane adsorption in porous materials [56].

The pioneering utilization of porous MOFs for methane storage in the early 2000s was reported [57]. In spite of their capacity of adsorbing large amounts of methane, highly porous MOFs have significant limitations due to high porosity and low density of frame works [58]. However, this limitation was surpassed by the late 2000s when PCN14 and Ni-MOF-74 were synthesized respectively [44]. These two MOFs displayed high methane storage capacities due to the high density of Open Metal Sites (OMSs) and appropriate pore spaces. Table 2. Show different porous material and their methane storage capacities.

\section{Storage of $\mathrm{CO}_{2}$}

Some basic requirements an adsorbent must have for it to be a suitable adsorbent for $\mathrm{CO}_{2}$ capture and storage include; low cost of base material, low heat capacity, high $\mathrm{CO}_{2}$ adsorption capacity/selectivity and mechanical/chemical stability under extensive recycling [65]. Although physical adsorbents such as MOFs, Zeolite and Carbon-based adsorbents prove to be effective $\mathrm{CO}_{2}$ adsorbents at low temperature and high pressure, they always adsorb water vapour in preference to $\mathrm{CO}_{2}$ and this results to low $\mathrm{CO}_{2}$ at low pressure [66] therefore, these adsorbents may not be appropriate sorption materials for post-combustion gas treatment.
In spite of the afore mentioned short coming, remarkable improvements have been achieved in the development of better $\mathrm{CO}_{2}$ adsorbents such as, Amine-modified porous materials, Zeolite-Metal-Organic Frameworks. These modified porous materials have large surface area and high carbon $\mathrm{CO}_{2}$ adsorption capacities even at low pressure.

Optimization of synthesis conditions and use of appropriate building blocks could be largely responsible for the increased tolerance to moisture and high $\mathrm{CO}_{2}$ adsorption selectivity exhibited by porous materials such as ZMOFs, COFs and Amine-functionalized MetalOrganic Frameworks as shown in Table 3.

\subsection{Application of MOFs for Liquid Phase Adsorption}

One of the most important liquid phase applications of MOFs is its use for purification of petroleum products. MOFs have found usefulness in the removal of Nitrogen Containing Compounds (NCCs) and Sulfur Containing Compounds (SCCs) from petroleum products [71]. Non-composite forms of MOFs possess large cavities inside their cage and this empty porous space can be utilized to adsorb and remove obnoxious materials [72]. Recent studies on the use of MOFs for industrial water treatment has been focused on the stability of MOFs in water, regeneration and the overall effect of the structure of MOFs on adsorption performance [73] thus, investigating the adsorption behavior of MOFs and their affinity to various liquid phase contaminants is very critical with respect to invention of novel porous adsorbent materials.

Table 2. Methane Storage capacity of some Porous Materials

\begin{tabular}{|l|l|l|l|}
\hline Porous Material & Surface area ${\left.\mathbf{~} \mathbf{m}^{\mathbf{2}} \mathbf{g}^{-1}\right)}^{\text {Methane Storage Capacity }}$ & Reference \\
\hline Activated carbon produced by $\mathrm{CO}_{2}+$ steam activation & 1548 & $145.89 \mathrm{v} / \mathrm{v}$ at ambient temperature & 59 \\
\hline Zeolite 13X-Al (III) & 561 & $2.1 \mathrm{mmol} / \mathrm{g}$ at $25{ }^{0} \mathrm{C}$ & 60 \\
\hline Zeolite Templated Carbon(ZTC-3) & 3591 & $4.1 \mathrm{mmol} / \mathrm{g}$ at room temperature & 61 \\
\hline ZJU-25 (MOF) & 2124 & $180 \mathrm{v} / \mathrm{v}$ & 62 \\
\hline Ni-MOF-74 & 599 & $200 \mathrm{~V} / \mathrm{V}$ at STP & 63 \\
\hline PCN -14 & 2176 & $230 \mathrm{v} / \mathrm{v}$ at $290 \mathrm{~K}$ and 35 bars & 64 \\
\hline
\end{tabular}

Table 3. $\mathrm{CO}_{2}$ Storage capacity of some porous materials

\begin{tabular}{|l|l|l|l|}
\hline Porous Material & Surface area & CO2 storage capacity & Reference \\
\hline Activated Carbon (AC-h) & $>3000 \mathrm{~m}^{2} \mathrm{~g}^{-1}$ & $21.29 \mathrm{mmolg}^{-1}$ & 67 \\
\hline Zeolite 13X & $2841 \mathrm{~m}^{2} \mathrm{~g}^{-1}$ & $7.4 \mathrm{mmolg}^{-1}(32 \mathrm{bars})$ & 68 \\
\hline MOF -177 & $4750 \mathrm{~m}^{2} \mathrm{~g}^{-1}$ & $35.5 \mathrm{mmolg}^{-1}(42 \mathrm{bars}, 298 \mathrm{~K})$ & 68 \\
\hline MOF- 210 & $6240 \mathrm{~m}^{2} \mathrm{~g}^{-1}$ & $54.5 \mathrm{mmolg}^{-1}(50 \mathrm{Bars}, 298 \mathrm{k})$ & 37 \\
\hline SBA-15 Azridine Polymer & $900 \mathrm{~m}^{2} \mathrm{~g}^{-1}$ & $4.0 \mathrm{mmolg}^{-1}(346 \mathrm{~K})$ & 69,70 \\
\hline
\end{tabular}


The adsorption behavior of high stable zirconium-based MOF for the removal of acid /organic dye from water was reported [64]. Similarly, the enhanced adsorptive removal of anionic / cationic dyes from single or mixed dye solutions using MOF PCN-222 yielded positive results [71].

The morphology and lead (II) ion removal capacity of Cobalt-Metal Organic Framework (Co-MOF) was studied and reported to be efficient [72]. Other studies of magnetic MOF and the extraordinary MOF (Fji-Hg) showed high adsorption capacity for removal of dyes and heavy metals $[73,74]$.

\section{Conclusion}

As Metal-Organic Frameworks keep serving the research community, they have equally opened new vista of opportunities by way of extending their coverage of utilization. Different preparation methods have produced various functionalities in MOFs thus, improving their range of applicability. The introduction of strong organic linkers has facilitated the synthesis of MOFs with structural integrity, permanent porosity and high surface area with capacities that exceed other known porous inorganic and organic materials.

The most patronized use of MOFs is adsorption and they have found usefulness in diverse industrial processes such as; removal of noxious and harmful substances from liquid/gaseous media, gas storage, separation, catalysis, drug delivery and purification. Functionalized MOFs can indeed show spectacular effects owing to the introduction of more active functional groups. Therefore, the performance and applicability of MOFs as sorbents in industrial processes depends on imparted functionality, high surface area and enhanced porosity.

\section{References}

[1] Ryder, M.R. and Tan, J.C. Nanoporous Metal Organic Framework Materials For Smart Applications. Material Science and Technology. 2014. vol.30. (3a).

[2] Gispert, J. R. Coordination Chemistry. Crystal Engineering: Metal Organic Frameworks (MOFs). WILEY-VCH. 2008.

[3] Chemistry World, October, 2009. http://www.rsc.org/chemistryworld.

[4] Yaghi, O.M., Li,G.and Li, H. Selective Binding and Removal of Guests in Microporous Metal-Organic Framework. Nature, 1995. 378, pp.703-706.

[5] Cheetam, A.K., Rao, C.N.R. and Feller, R.K. Chem. Commun. 2006. 4780.

[6] United States of America, Department of Energy, Basic Research Needs for Carbon Capture: Beyond 2020. 2010.

http://go.nature.com/ibM9qj.

[7] Park,H., Britten, J.F., Mueller,U., Lee, J. Li, J. and Parise, J.B. Chem. Mater. 2007. 19, 1302.

[8] United States of America, Department of Energy. Basic Research Needs for the Hydrogen Economy. 2004. http://go.nature.comGZYzy6.

[9] Wang, S.B. and Peng, Y.L. Natural Zeolites as Effective Adsorbents in Water and Wastewater Treatment. Chem. Eng. J. 2010.156, pp.11-24.

[10] Namazi, H., Heydari, A. and Pourfarzollar. A Synthesis of Glycoconjugated Polymer based on Polystyrene and Nanoporous $\beta$-Cyclodextrin to remove Copper II from Water Pollution. Int. J. Polym. Mater. Biomater. 2014. 63, pp. 1-6.

[11] Zheng, L., Ding, A.Z. and Ding, W.C. Compare Study of a New type of Adsorbent and 2 Traditional Adsorbents on their
Efficiency for As(v) Adsorption. In Proceedings of $20104^{\text {th }}$ International Conference on Bioinformatics and Biomedical Engineering (ICBBE). Chengdu, China. 2010. pp. 1-4.

[12] Ongkudon, M..C., Kansil, T. and Wong, C. Challenges and Strategies in the Preparation of Large volume Polymer-based monolithic Chromatography Adsorbents. J. Sep. Sci. 2014. 37. pp. 455-464.

[13] Lata,S. and Samadder, S.R. Removal of Arsenic from Water Using Nano Adsorbents and Challenges: A Review. J. Environ. Manag. 2016. 166, pp. 387-406.

[14] Ding, L.H., Rahimi, P., Hawkins, R., Bhatt, S. and Shi,Y. Naphthenic Acid Removal from Heavy Oils on Alkaline -earth metal oxides and Zinc oxide Catalysts. App. Catal. Gen.371, 2009. pp. 121-130.

[15] Wang, X.Y., Du, Y. and Ma, J. Novel Synthesis of Carbon Sphere supported Nano scale Zero-valent Iron for removal of Metronidazole. App.Surf. Sc. 390, 2016. pp. 50-59.

[16] Bowman, J.K. Alfred Werner Revisited: Coordination Chemistry of Anions. Accounts of Chemical Research.38, 2005. pp. 671-678.

[17] Furukawa, H., Cordava, K.E., O’Keefe, M. and Yaghi, O.M. The Chemistry and Application of Metal-Organic frameworks. Science. 341. 123044.

[18] Kitagawa, S., Kituara,R. and Noro, S.I. (2004). Functional Porous Coordination Polymers. Angewandte Chemie. International edition, 43, 2013. pp. 2334-2375.

[19] Moulton,B. and Zworotko,M.J. From Molecules to Crystal Engineering: Supramolecular Isomerism and Polymorphism in network Solids. Chemical Reviews. 101, 2001. pp.1629-1658.

[20] Eddaoudi, M., Li, H. and Reinek, T. Design and Synthesis of Metal-Carboxylate Framework with Permanent Micro porosity. Topics in Catalysis. 905. 1999. pp. 105-111.

[21] Li, H.,Eddaoudi,M., O’Keefe, M. and Yaghi,O.M. Design and Synthesis of an Exceptionally Stable and highly Porous MetalOrganic Framework. Nature, 402. 1999. pp. 276-279.

[22] O’Keefe, M. and Yaghi, O.M. New Micro-porous Crystalline Materials: MOFs, COFs and ZIFs. Transactions of the Symposium held at the 2010, American Crystallographic Association Annual meeting, Chicago IL, July, 2010. pp. 24-29.

[23] Schoedel, A. and Yaghi, O.M. Porosity in Metal-Organic Compounds, Microcyclic and Spramolecular Chemistry : How Izatt-Christensen Award winners shaped the field .First edition, John Wiley and Sons, Ltd, 2016. pp. 201-219.

[24] Eddaoudi, M., Kim, J. and Rosi, N Systematic design of Pore Size and Functionality in Isorecticular MOFs and their Application in methane storage. Science, 295. 2002. pp.469-472.

[25] Tranchemontagne, D.J., Hunt, J.R. and Yaghi,O.M. Room Temperature Synthesis of Metal-Organic Frameworks: MOG-5, MOF-74, MOF-177, MOF-199 and IRMOF-0. Tetrahedron. 64, 2008. pp.8553-85577.

[26] Hong, W.Y., Perera, S.P. and Burrows, A.D. Manufacturing of Metal-Organic Framework Monoliths and their Application in $\mathrm{CO}_{2}$ Adsorption. Microporous and Mesoporous Materials. 2015. 214, pp. 149-155.

[27] Dey, C., Kundu, T., Bishnu, P., Mallick, A. and Banerjee, R. Crystalline Meta-Organic Frameworks (MOFs): Synthesis, Structure and Function. Acta. Cryst. B 70, 2014. pp.7-10.

[28] Shen, L. Synthesis, Characterization and Application of MetaOrganic Frameworks. Dissertation Submitted to the Graduate College of the University of Illinois at Urbana - Champaign, Urbana - Illinois, 2012. pp. 6-7.

[29] Lee, Y.R., Kim, J. and Ahn,W.S. Synthesis of Metal-Organic Frameworks: A mini review. Korean Journal of Chemical Engineering. 30(9), 2013. pp. 1667-1680.

[30] He, J.H., Zhang, Y.T., Pan, Q.H., Yu, J.H., Ding, H. and Xu, R.R. Microporous Mesoporous Materials. 90, 2006. pp. 145-152.

[31] Hindelang, K., Vagin, S.I., Anger,C. and Rieger, B. Tandem Post Synthesized modification for Functionalized Metal-Organic Frameworks via Epoxidation and subsequent Epoxide ring opening. Chem. Commun. 48, 2012. pp. 2888-2890.

[32] Carson, C.G., Brown, A.J., Sholl, D.S. and Nairs, S. Sonochemical Synthesis and Characterization of Submicrometer crystals of Metal- Organic Framework $\mathrm{Cu}\left[\left(\right.\right.$ hfipbb) $\left.\left(\mathrm{H}_{2} \text { hfipbb }\right)_{0.5}\right]$. Cryst. Growth Des. 11(10), 2011. pp. 4505-4510.

[33] Yoo, Y., Valera-Guerrero, V. and Jeong, H. Isorecticular Metal-Organic Frameworks and their membranes with enhanced crack resistance and moisture stability by surfactant-assisted drying, Langmuir. 27(6), 2011. pp. 2652-2657. 
[34] Martinea,A., Juan-Alcaniz, J., Sera-Crespo, P., Kapteijn, F. and Gascon, J. Electrochemical synthesis of some Archetypical Zn2+, $\mathrm{Cu} 2+$, and $\mathrm{Al} 3+$ Metal-Organic Frameworks. Cryst. Growth Des. 12(7), 2012. pp. 3489-3498.

[35] Jean-Louis, D. and Friŝĉ iĉ, T. Mechanochemistry: A force of Synthesis. ACS, Cent. 2016.

[36] Hann, T.T., Li, C.F., Guo,X.Y., Huang, H.L., Liu,D.H. and Zhong,C.L. In-situ Synthesis of SiO @MOF Composites for high Efficiency Removal of Aniline from Aqueous Solutions. App.Surf. Sc. 390. 2016. pp. 506-512.

[37] Martin,R.L. and Haranczyk. Optimization-Based Design of MetalOrganic Framework Materials. Journal of Chemical Theory and Computation. Vol. 9 (6), 2013. pp. 2816-2825.

[38] Bauman, T.F. Metal-Organic Frameworks: Literature Survey and Recommendation of Potential Sorbent Materials. (Review of MOF Materials). Lawrence Livermore National Laboratory, LLNL-TR430112. 2010.

[39] Bae, Y.S. and Snurr, R.O. Development and Evaluation of Porous Materials for Carbon dioxide Separation and Capture. Angew. Chem. Int. Ed. Engl. Vol.50 (49), 2011. pp. 11586-11596.

[40] Li, J.R., Kuppler,R.J. and Zhou, H.C. Selective Gas Adsorption Separation in Metal-Organic Frameworks. Chem. Soc. Rev: 38 (5), 2009. pp. 477-504.

[41] Ma, S. Gas Applications of Porous Metal-Organic Frameworks. Pure. Appl. Chem, Vol.81 (12), 2009. pp. 2235-2251.

[42] Dybtsev, D.N., Chun, H., Yoon, S.H., Kim,D. and Kim,K. Microporous Manganese Formate: A Simple Metal-Organic Porous Material with High Framework Stability and High Selectivity gas Sorption Properties. Journal of American Chemical Society. 126 (1), 2004. pp. 32-33.

[43] Ma, S., Wang, X.S., Collier, C.D., Mani, E.S. and Zhou, H.C. Inorganic Chemistry. 2007. 46. 8499.

[44] Rowsell, J.I.C and Yaghi, O.M. Effects of Functionalization, Catenation and Variation of the Metal Oxide and Organic Linking Units on the low Pressure Hydrogen Adsorption properties of Meta-Organic Frameworks. J.Am. Chem. Soc. 128, 2006. pp. 1304-1315.

[45] Helmolt von, R. and Eberle, U. Fuel Cell Vehicles: Status 2007. Journal of Power Sources. Vol.165 (2), 2007. pp. 833-843.

[46] Kunowsky, M., Marco-Lozar, J.P and Linares-Solano, A. Review Article: Material Demands for Storage Technologies in a Hydrogen Economy. Journal of Renewable Energy. Hindawi Publishing Corporation. Article I.D: 878329. 2013.

[47] Eberle, U., Felderhoff, M. and Schüth. F. "Chemical and Physical Solutions for Hydrogen Storage. Angewandte Chemie-International Edition. Vol.48 (36), 2009. pp. 6608-6630.

[48] Vitillo, J.G., Richiardi, G., Spoto,G. and Zechinna, A. Theoretical Maximum Storage of Hydrogen in Zeolitic Frameworks. Physical Chemistry, Chemical Physics.vol. 7 (23), 2005. pp. 3948-3954.

[49] Nijkamp, M.G., Raaymakers, J.E.M., Van Dillen, A.J. and De Jong, K.P. Hydrogen Storage Using Physisorption Materials Demands. Applied Physics. A. VOL. 72 (5). 2001. pp. 619-623.

[50] Goldberg, D., Bando,Y. Tang, C. AND Zni, C. Boron Nitride Nanaotubes. Advanced Materials. Vol. 19 (18), 2007. pp. 2413-2432.

[51] Portehault, D., Giordano, C. and Gervais. High Surface Area Nano Porous Carbon Nitrides for Hydrogen Storage. Advanced Functional Materials. Vol. 20 (11), 2010. pp. 1827-1833.

[52] Tian, Y.H., Buckley, C.E., Wang, S.B. and Zhou, M.E. Enhanced Hydrogen Storage Capacity in Carbon Aerogels Treated with KOH. Carbon. Vol. 47 (8), 2009. pp. 2128-2130.

[53] Lee, Y.Y., Wood, C.D., Bradshaw, D., Rosseinsky, M.J. and Cooper, A.J Hydrogen Adsorption in Microporous Hypercrosslinked Polymers. Chemical Communications. 25. 2006. pp.2670-2672.

[54] Saha, D. and Deng, S. Hydrogen Adsorption on Metal-Organic Framework-177. Tsinghun Science and Technology. vol.15 (4). 2010. pp. 363-376.

[55] Mohd Saufi, M.Z. and Syed Shatir, A.S.H. Methane Adsorption Performance of Palm Kernel Derived Carbon Material Activated using CO2 - Steam Sequential combination. Malaysian Journal of Analytical Sciences. Vol. 20 (6). 2016. 1390-1397.

[56] Noro, S., Kitagawa, S., Kondo, M. and Seki, L. A New Methane Adsorbent. Porous Coordination Polymer. 39 (12). 2000. pp. 2081-2084.

[57] Duan, X., Yu, J., Cai, J., He, Y., Wu, C., Zhou, W., Yildirimi, T, Zhang, Z., Xiand, S., O'Keefe, M., Chen, B. and Qian.B. A Microporous Metal-Organic Framework of Rare Sty Topology for High $\mathrm{CH}_{4}$ Storage at Room Temperature. Chem. Comm. 49. 2013. pp. 2043-2045.

[58] Ambia, M., Sedighi, A. and Salehi, S. Evaluation of Methane Adsorption on Modified Zeolite 3X. Iranica Journal of Energy and Environment. Vol. 7 (1) 2016. pp. 221-225.

[59] Stadie, N.P., Murialdo, M., Ahn, C.C. and Fultz, B. Unusual Entropy of Adsorbed Methane on Zeolite Templated Carbon. Journal of Physical Chemistry. 119 (47). 2015. pp. 26409-26421.

[60] Wu, H., Zhou, W. and Yildirimi, T. High Capacity Methane Storage in Metal-Organic Framework $\mathrm{M}_{2}$ (dhtp): The important Role of Open Metal Sites. Journal of the American Chemical Society. 131 (13), 2009. pp. 4995-5000.

[61] Ma, S. Gas Adsorption Applications of Porous Metal-Organic Frameworks. Pure. Appl. Chem. Vol. 81(12). 2009. pp. 2235-2251.

[62] Sayaria, A., Belmabkhout, Y and Serna-Guerrero, R. Flue Gas Treatment via $\mathrm{CO}_{2}$ Adsorption. Chemical Engineering Journal. 230. 2011. pp. 380-388.

[63] Kelut, P., Kulkarni, K. and Kulkarni, A.D. $\mathrm{CO}_{2}$ Adsorption by various Catalysts. Chemical and Process Engineering Research. Vol. 18, 2014. pp. 7-15.

[64] Zhang, Z.J., Zhang, W., Chen, X., Xia, Q.B. and Li, Z. Adsorption of $\mathrm{CO}_{2}$ on Zeolite $13 \mathrm{X}$ and Activated Carbon with Higher Surface Area. Sep. Sc. Technol. 45. (5), 2010. pp. 710-719.

[65] Millward, A.R. and Yaghi, O.M. Metal-Organic Frameworks with Exceptional High Capacity for Storage of Carbon dioxide at Room Temperature. Journal of the American Chemical Society. Vol. 127 (51). 2005. pp. 17998-17999.

[66] Drese, J.H., Choi,S., Lively, R.P., Koros, W.J., Fauth, D.J., Gray, M.L. and Jones, C.W. Structure, Property relationships of Hyper branched Amino silica $\mathrm{CO}_{2}$ Adsorbents. Advanced Functional Materials.vol.19 (23). 2009. pp. 3821-3832.

[67] Jörg, P.T., Girgsdies, F., Schlogl and Hess, C. Pore Structure and Surface AREA OF Silica SBA-15: Influence of Washing and Scale-up. Beistein Journal of Nanotechnology. 2, 2011. pp. 110-119.

[68] Ahmed, T., and Jhung, S.H. Composites of Metal-Organic Framework: Preparation and Application in Adsorption. Materials Today. Vol.17 (3), 2014. pp. 136-146.

[69] Khan, N.A., Hasan, Z. and Jhung, S.H. Adsorption and Removal of Sulfur or Nitrogen containing Compounds with Metal-Organic Frameworks (MOFs). Adv. Porous. Mater. Vol.1 (1), 2013. pp. 91-102.

[70] Burtch, N.C., Jsuja, H. and Walton, K.S. Water Stability and Adsorption in Metal-Organic Frameworks. Chem. Rev. 114. 2014. pp.10575-10612.

[71] Zhang, K.D., Zhan, Z.Q., Tsai, F.C., Yu, X.Y., Zeng, X.Z., Jiang, X.Z., Jiang, T., Shi,D. and Chang, C.J. Adsorption behavior of High Stable Zr-Based MOFs for the Removal of Acid Organic Dye from water. Materials.10 (205), 2017. pp. 1-11.

[72] Shooto, N. D., Ayawei, N., Wankasi, D., Sikhwivhilu, L. and Dikio, E. D. Study on Colbat-Metal Oarganic Framework Materials as adsorbent for Lead ions Removal in Aqueous Solutions. Asia Journal of Chemistry. 28(2). 2016. pp. 277-281.

[73] Zhao, X., Lius, S., Tang, Z., Niu, H., Cai, Y., Meng, W., Wu, F. and GEISY, J.P. Synthesis of Magnetic Metal-Organic Framework (MOF) for Efficient Removal of Organic Dyes from Water. Scientific Reports. 2015. 5, 11849.

[74] Xue, H., Chen, Q., Jiang, F., Yuan, D., Lv, G., Liang, L., Liu, L. and Hong, M. A regenerative Metal-Organic Framework fro Reversible Uptake of Cd(II): From Effective Adsorption to In-situ Detection. Chemical Science. 7, 2016. pp. 5983-5988. 